\title{
Auto-retrato
}

\section{caminhos pelo desconhecido}

\section{Self-portrait}

a journey through the unknown

\begin{abstract}
"Se de imediato não vemos auto-retrato, 0 título sugere procurar um equivalente dele.

Ver nas fotografias algo como um ver através. E assim por diante."
\end{abstract}

Luiz Gonzaga Leal

"Fotografar é poder enxergar o invisível".

Foi com essa visão que percorri os labirintos do Hospital Ulysses Pernambucano em abril de 2000. Fiquei encantada com o trabalho que ali estava sendo desenvolvido.

"Tudo muda a partir do olhar". Foi o que constatei nesta viagem pelas entranhas do hospital. No início era apenas um ensaio fotográfico sobre a loucura, mas a partir do primeiro encontro percebi "quantas coisas podem ser vistas, quantas coisas devem ser mostradas! Eu quis ver tudo!". No projeto de ensaio e de oficina fotográfica para os pacientes, eles viraram fotógrafos, modelos, intérpretes de uma vida também cheia de afeto, beleza, doçura e fragilidade.

Auto-Retrato não é o retrato da loucura, mas da vida, da emoção, dos sonhos.

É o meu retrato, e o de cada um de nós.

$O$ retrato de nossa alma.

Gyzia Pimentel

Gysia Dias Pimentel, fotógrafa, idealizadora e coordenadora do projeto Auto-retrato - caminhos pelo desconhecido, uma oficina e ensaio fotográfico com os pacientes do Hospital Ulysses Pernambucano, Recife. <gyzia@uol.com.br>

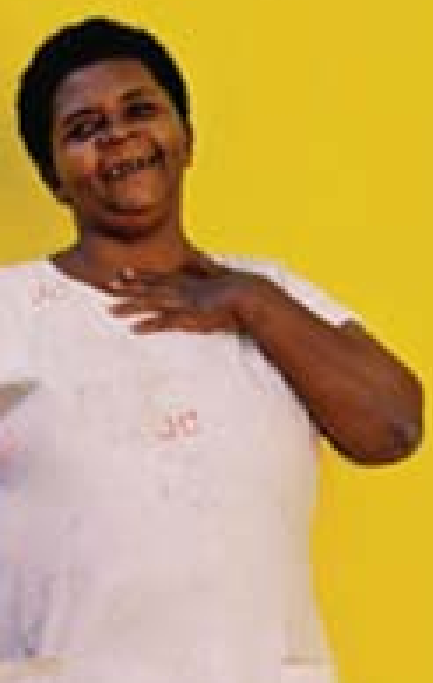



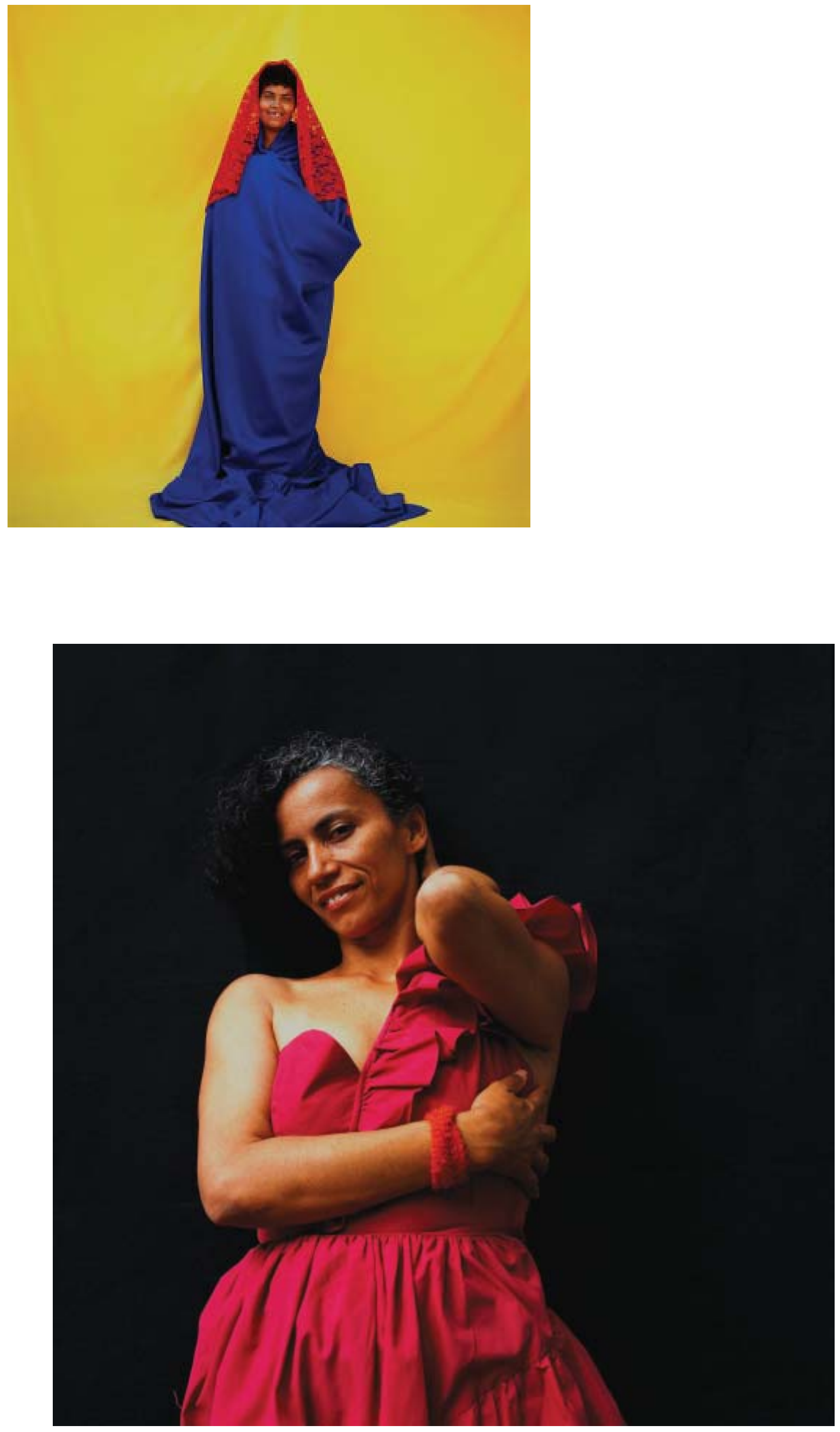

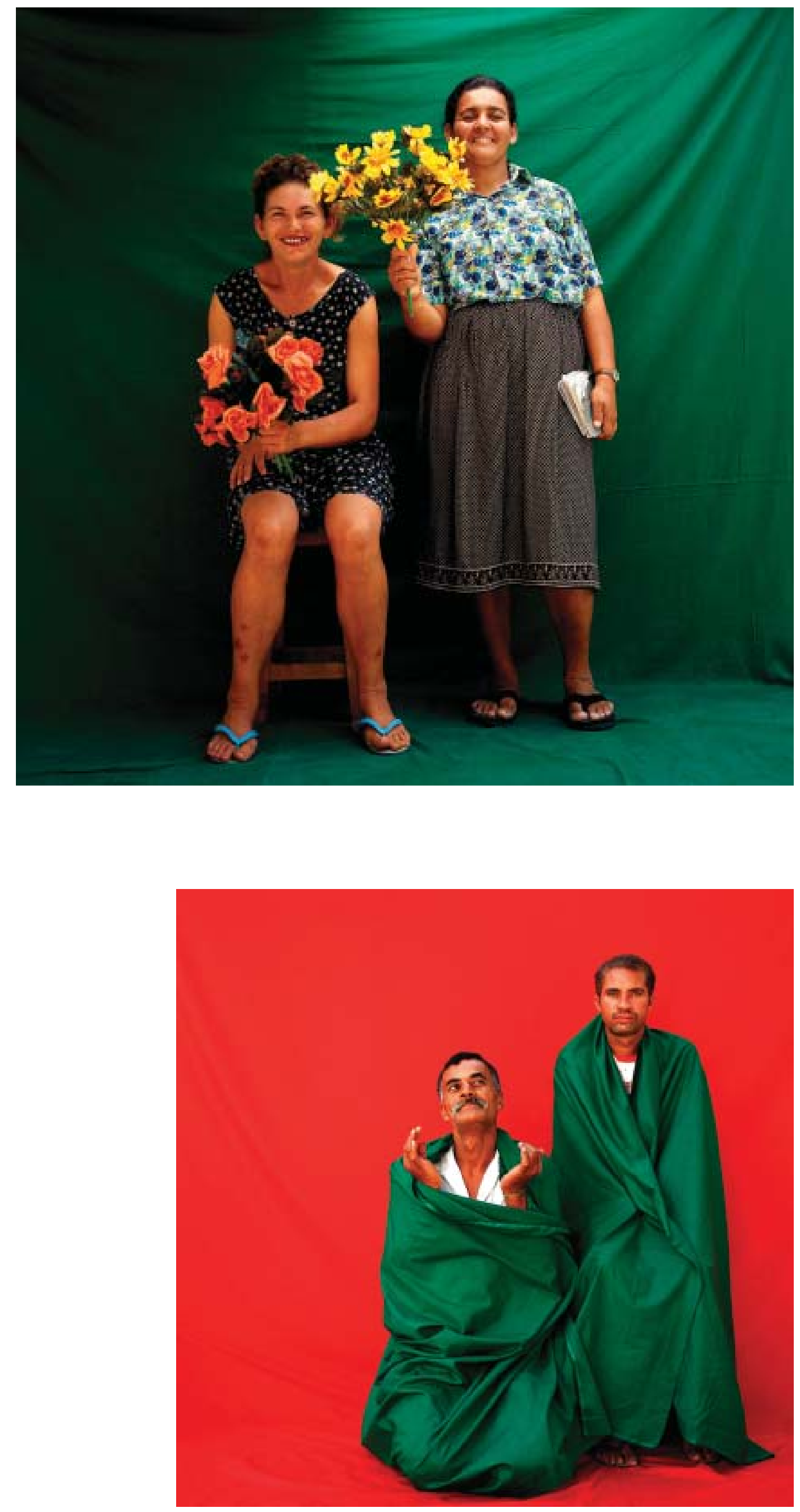


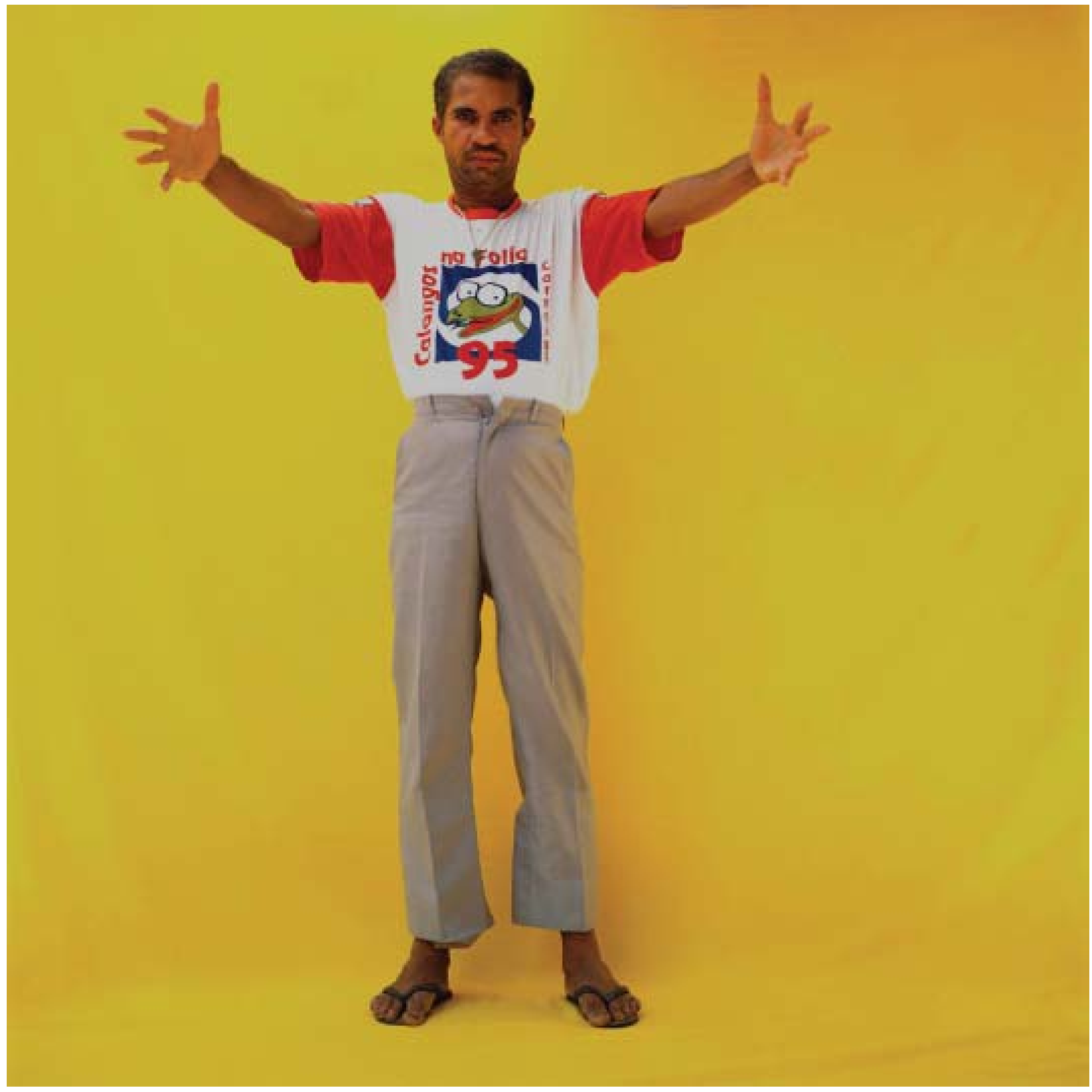


São comuns na literatura - especializada ou não - as imagens de doentes mentais... sombrias, tristes, emolduradas pela solidão. Imagens captadas por um olhar que petrifica, imobiliza, captura o sujeito fixando-o em sua ausência. O trabalho de Gyzia, junto com os pacientes do Hospital ulysses Pernambucano, utiliza uma outra química para fazer revelações. No lugar de mostrar "aquilo de que sou excluído" (Barthes), as imagens que vão surgindo pelo jogo lúdico de colocar-se atrás ou diante das lentes da câmera revelam, ao mesmo tempo, o brilho da surpresa, as cores do prazer, o deslumbramento que possibilita a emergência do desejo. Capturam também o sujeito. Sem fixá-lo, propõem remetê-lo a outro lugar, lugar do vir a ser, lugar de sujeito desejante. A oficina de fotografias, este ensaio $e$ todo o projeto do ciclo Iluminuras desenvolvido no hospital, cumprem a função de deslocar o olhar ou, numa linguagem mais própria ao tema, fixar o foco em ângulo que permita a criação de subjetividades.

Maria Amélia Lyra Diretora do Hospital Ulysses Pernambucano

Auto-retrato - caminhos pelo desconhecido propõe um percurso pelo mistério da ruptura, temporária ou permanente com a realidade. Mergulha no território dos desassossegados. Estas imagens não se submetem. Pelo contrário, captam os movimentos de dignidade dos que pulsam, incendiados, em todas as direções. Com isso, dão golpes nos preconceitos. Não entendo bem o processo de loucura... Penso que o que separa a chamada saúde psíquica da loucura dita oficial é um fio tênue que pode romper-se a qualquer momento. Portanto, ninguém deveria se vangloriar da robustez da saúde mental. Vejo reflexos da tensão vital de cada um dos envolvidos com o projeto. Um ato a mais em favor da vida. Porque é preciso construir algo por meio do qual possamos nos fertilizar.

Ivana Moura Jornalista 
Eu posso compreender o porquê de pessoas com tal teor de sensibilidade e afeto viverem aladas em seus pensamentos. E este ensaio fotográfico me faz compreender mais ainda. Sinto por eles um respeito enorme. È um mistério absurdo! Revela sonoridades e cores... mostra que o interessante é olhar. É como olhar, é quem olha - o olhador. Observar, ver o que não se viu. Ver diferente o que já foi visto. Onde está a beleza? No objeto? Ou no universo interno de quem reconhece? As fotografias não querem impressionar, querem falar, comunicar uma vez mais o incomunicável de uma visão individual. Um timbre singular, que não pode ser dito, nem tão pouco calado. Algo aligeira-se dentro de cada um como sopro, tocando-os à surdo, acariciando as sombras, os contornos, a leveza que transforma as coisas.

Apaziguadoras imagens. Diante desta assombrosa experiência disse-me um deles: "Os olhos da gente não tem fim".

Luiz Gonzaga Pereira Leal Supervisor Geral do Centro de Atividades-HUP, coordenador do Ciclo Iluminuras 